\title{
TASK channels in arterial chemoreceptors and their role in oxygen and acid sensing
}

\author{
Keith J. Buckler
}

Received: 1 October 2014 / Revised: 6 January 2015 / Accepted: 7 January 2015 /Published online: 28 January 2015

(C) The Author(s) 2015. This article is published with open access at Springerlink.com

\begin{abstract}
Arterial chemoreceptors play a vital role in cardiorespiratory control by providing the brain with information regarding blood oxygen, carbon dioxide, and $\mathrm{pH}$. The main chemoreceptor, the carotid body, is composed of sensory (type 1) cells which respond to hypoxia or acidosis with a depolarising receptor potential which in turn activates voltage-gated calcium entry, neurosecretion and excitation of adjacent afferent nerves. The receptor potential is generated by inhibition of Twik-related acid-sensitive $\mathrm{K}^{+}$channel 1 and 3 (TASK1/TASK3) heterodimeric channels which normally maintain the cells' resting membrane potential. These channels are thought to be directly inhibited by acidosis. Oxygen sensitivity, however, probably derives from a metabolic signalling pathway. The carotid body, isolated type 1 cells, and all forms of TASK channel found in the type 1 cell, are highly sensitive to inhibitors of mitochondrial metabolism. Moreover, type1 cell TASK channels are activated by millimolar levels of MgATP. In addition to their role in the transduction of chemostimuli, type 1 cell TASK channels have also been implicated in the modulation of chemoreceptor function by a number of neurocrine/paracrine signalling molecules including adenosine, GABA, and serotonin. They may also be instrumental in mediating the depression of the acute hypoxic ventilatory response that occurs with some general anaesthetics. Modulation of TASK channel activity is therefore a key mechanism by which the excitability of chemoreceptors can be controlled. This is not only of physiological importance but may also offer a therapeutic strategy for the
\end{abstract}

This article is part of the special issue on " $\mathrm{K}_{2 \mathrm{P}}$ channels".

\section{K. J. Buckler $(\bowtie)$}

Department of Physiology Anatomy and Genetics, University of

Oxford, Parks Rd, Oxford, OX1 3PT, England

e-mail: keith.buckler@dpag.ox.ac.uk treatment of cardiorespiratory disorders that are associated with chemoreceptor dysfunction.

Keywords K2P channel $\cdot$ Potassium channel $\cdot$ TASK channel $\cdot$ Carotid body $\cdot$ Hypoxia $\cdot$ Oxygen sensing

\section{Arterial chemoreceptors: background to structure and function}

Arterial chemoreceptors are among the smallest organs in our bodies. Their function is to serve both cardiovascular and respiratory control centres in the brainstem with vital information concerning the chemical composition of arterial blood. There are two main clusters of chemoreceptor tissue, that in the vicinity of the common carotid artery, which normally forms well-defined bilateral organs called carotid bodies, and that associated with the underside of the aortic arch (and sometimes in the vicinity of the pulmonary and subclavian arteries), which form less well-defined aggregates of tissue called aortic bodies. Of these, it is the carotid bodies which probably have the most important physiological role and which have been the most extensively studied. The carotid body is composed of small clusters of type 1 (glomus) cells partially enveloped by glial-like type 2 (sustentacular) cells. Type 1 cells are innervated by afferent neurons from the carotid sinus nerve which originate in the petrosal ganglion and project to the nucleus tractus solitarii. The carotid body is richly vascularised and is believed to have the highest resting blood flow per unit weight of any organ in the body (for further background to these organs, the reader is directed to a number of extensive reviews [31, 41, 45]).

The carotid body has a number of sensory modalities. Perhaps the most striking is the ability to sense changes in oxygen 
levels in the blood. The response of an isolated carotid body or chemoreceptor cell to a fall in oxygen levels is manifested within seconds. Acute oxygen sensing of this form is only recognised in a few other tissues, i.e. pulmonary arterioles, neuroepithelial bodies of the lung and neonatal adrenal medullary chromaffin cells [135]. The carotid body is also sensitive to acidosis and $\mathrm{CO}_{2}$ (probably via changes in $\mathrm{pH}_{\mathrm{i}}$, see [41]). In addition to natural stimuli, the carotid body is also notable for being excited by mitochondrial poisons $[3,48,87$, 117] which may reflect a metabolic sensing capacity. In recent years, the carotid body has also been proposed to act as a blood glucose sensor [97, 144]. This is a controversial area with different groups and experimental approaches providing conflicting evidence $[5,25,43]$. It is possible that glucose sensitivity may again derive from some form of metabolic sensing pathway that is dependent upon both extracellular glucose availability and glycogen reserves [49].

Chemotransduction mechanisms are best described for oxygen sensing and $\mathrm{acid} / \mathrm{CO}_{2}$ sensing. In both cases, the basic mechanism is a classical sequence of electrical excitation of the primary sensory cell, the type 1 cell, which leads to an influx of calcium and neurosecretion [13-15]. The type 1 cell contains a rich diversity of neurotransmitters which fulfil a variety of roles [41, 45, 89]. For the sake of brevity, however, current evidence suggests that ATP is probably the main excitatory transmitter released from the type 1 cell. This excites afferent nerve endings via P2X2/P2X3 receptors [114, 147, 148].

\section{Role of background K-currents and other channels in mediating electrical signalling}

From the above description, it is clear that electrical signalling plays a central role in the transduction of chemostimuli. The basic model of electrical signalling is that hypoxia and acidosis modulate specific ion channels in the type 1 cell to elicit a depolarising receptor potential which is often accompanied by spontaneous action potentials. These electrical events incorporate the activation of voltage-gated calcium channels which mediate a large influx of calcium ions resulting in a substantive elevation of the intracellular calcium ion concentration $[8$, $14,15]$. Type 1 cells express a number of different ion channels including Twik-related acid-sensitive $\mathrm{K}^{+}$channels (TASK channels) ${ }^{+}$, an uncharacterised background $\mathrm{Na}^{+}$conductance, $\mathrm{Cl}^{-}$channels, a calcium-activated cation channel, Land N-type voltage-gated calcium channels, voltage-gated $\mathrm{Na}^{+}$channels (in some species), voltage-gated (delayed rectifier) $\mathrm{K}^{+}$channels and large conductance calcium-activated $\mathrm{K}^{+}$ channels (maxi K channels, $\mathrm{BK}_{\mathrm{Ca}}$ ) $[8,17,19-21,35,38,53$, $72,74,101,104,113,120,121,130]$. The functional role of all of these channels however is not necessarily well understood.
The resting potential of acutely isolated type 1 cells in vitro in physiological media at $35-37 \mathrm{C}$ as recorded using the perforated patch technique is around -50 to $-60 \mathrm{mV}[9,14,15$, $113,139]$. As in other cells, this resting potential represents a balance between inward currents, most likely carried by $\mathrm{Na}^{+}$ ions, and outward currents carried by $\mathrm{K}^{+}$ions and the $\mathrm{Na}^{+} / \mathrm{K}^{+}$ pump. The resting (background) $\mathrm{K}^{+}$conductance of the type 1 cell was estimated at around $340 \mathrm{pS}[8]$ which, at a membrane potential of $-50 \mathrm{mV}$, would generate an outward $\mathrm{K}^{+}$current of around $14 \mathrm{pA}$. This resting potassium conductance is largely voltage insensitive and appears to be mediated primarily by TASK channels [17]. The channels responsible for resting $\mathrm{Na}^{+}$ ion influx have not yet been identified although preliminary estimates suggest that this is not an insignificant current (approx. $-20 \mathrm{pA}$ ) $[8,20]$. In the steady state, the corresponding $\mathrm{Na}^{+}$influx would have to be balanced by $\mathrm{Na}^{+} / \mathrm{K}^{+}$pump activity which, with a coupling ratio of $3 \mathrm{Na}^{+} / 2 \mathrm{~K}^{+}$, would generate an additional outward current of about $7 \mathrm{pA}$. Thus, the charge movements through these three pathways are roughly in balance. It is probable that other resting membrane currents also exist, we know little about $\mathrm{Cl}^{-}$currents in type 1 cells for instance.

The resting background $\mathrm{K}^{+}$conductance is inhibited in response to hypoxia and acidosis $[8,15,17]$. Under typical experimental hypoxic conditions, the background $\mathrm{K}^{+}$conductance may be reduced by between 50 and $80 \%$ [17, 56]. A $50 \%$ reduction in background $\mathrm{K}$ conductance would result in a decline in the outward resting K-current from 14 to $7 \mathrm{pA}$, thus creating an imbalance between resting inward and outward currents. The resultant net inward current $(-7 \mathrm{pA})$, carried predominantly by $\mathrm{Na}$ ions, will then bring about a rapid membrane depolarisation. Thus, the initial membrane depolarisation is primarily a consequence of background (TASK) $\mathrm{K}^{+}$channel inhibition but is probably driven by $\mathrm{Na}^{+}$ ion influx.

Whilst we can account for the onset of membrane depolarisation in response to hypoxia through TASK channel inhibition, we do not yet know what defines the magnitude of the resulting receptor potential and any consequential electrical activity. A number of other channels are likely to play an increasingly significant role as the cell depolarises. Of particular relevance are high threshold voltage-gated $\mathrm{Ca}^{2+}$ channels which become active at potentials positive to $-50 \mathrm{mV}[15,38$, $130]$ and voltage-gated $\mathrm{Na}^{+}$channels (in those species whose type 1 cells express them, e.g. rabbit [35]). This would add a further drive to depolarisation with positive feedback between depolarisation and $\mathrm{Ca}^{2+}$ and $\mathrm{Na}^{+}$channel activation resulting in an action potential. In addition, a calcium-activated cation channel has recently been found in the type 1 cell. This channel becomes active during hypoxia due to the elevation of intracellular calcium (via voltage-gated $\mathrm{Ca}$ channels) and would thus contribute to a positive feedback driving further membrane depolarisation and $\mathrm{Ca}$ influx [53]. 
Counterbalancing these inward currents, we would expect depolarisation to activate voltage-gated $\mathrm{K}$ channels and elevation of cytosolic calcium to activate calciumactivated potassium channels both of which would generate outward repolarising current (and thus attenuate $\mathrm{Ca}$ influx). It is notable in this context that the large conductance calcium-activated potassium channels (maxi-K channels) in type 1 cells are also inhibited by hypoxia and acidosis [101, 102]. Inhibition of maxi-K channels may therefore facilitate electrical and calcium signalling in response to physiological stimuli. The exact role of these channels in controlling cellular electrical activity and calcium influx during excitation however requires further investigation. There may also be other chemosensitive currents present, e.g. acid-sensing ion channels (ASICs) can be activated under severe acidic conditions and may contribute a very brief depolarising current [126] in response to a rapid fall in $\mathrm{pH}$. In addition, there may be other oxygen-sensitive currents present in type 1 cells [129]. Figure 1 shows a schematic of the main ion channels present in rat type 1 cells and their proposed role in electrical signalling.

\section{Calcium signalling in type 1 cells}

Calcium influx and elevation of calcium concentration in the type 1 cell is thought to be a prerequisite for stimulus evoked neurosecretion [18, 106, 108]. The mechanisms of intracellular calcium regulation in type 1 cells have however received relatively little attention. The primary cause of the rise in $\left[\mathrm{Ca}^{2+}\right]_{\mathrm{i}}$ in response to hypoxia or acidosis is calcium influx through voltage-gated channels as described above [14, 15]. Calcium induced calcium release via ryanodine receptors is thought to be of minor significance since caffeine releasable stores seem small in type 1 cells [15]. Type 1 cells do however have intracellular calcium stores from which $\mathrm{Ca}^{2+}$ release may be evoked by receptor-activated signalling pathways (e.g. muscarinic receptors [32]), and it is possible that these have an important role to play in calcium signalling in vivo where the type 1 cell will be exposed to a variety of autocrine, paracrine and neurocrine factors [89]. $\mathrm{Na}^{+} / \mathrm{Ca}^{2+}$ exchange seems to have minimal role in mediating either calcium influx or efflux in type 1 cells [15], so we presume that the primary mechanism of $\mathrm{Ca}^{2+}$ extrusion from the cell is by a plasma membrane $\mathrm{Ca}^{2+} / \mathrm{H}^{+}$ATPase although this remains to be confirmed. The role of mitochondria in calcium buffering has also not yet been studied, but given the exceptional sensitivity of mitochondrial membrane potential to hypoxia, it is possible that mitochondrial calcium uptake may be constrained in hypoxia which could facilitate $\mathrm{Ca}^{2+}$ signalling.

\section{Molecular and biophysical properties of TASK channels in type 1 cells}

Notwithstanding the importance of numerous channels, pumps and receptors involved in type 1 cell signalling; it is clear that TASK channels play a key role in initiating the receptor potential in response to chemostimuli. This event is pivotal to the chemotransduction process.

It was the acid sensitivity of the background $\mathrm{K}^{+}$current in type 1 cells, amongst other features, that led to the initial identification of this current as being TASK-like [17]. Other TASK-like features include little voltage sensitivity, other than that which may be ascribed to Goldman-Hodgkin-Katz type rectification, and a resistance to the classical $\mathrm{K}$ channel blockers TEA and 4-AP [8, 17]. Cell attached patch recordings from type 1 cells show abundant potassium channel activity at the resting potential. These channels have fast flickery kinetics with short bursts of rapid openings with estimated mean open time constant of $0.3 \mathrm{~ms}$, a short closed time constant of $0.1 \mathrm{~ms}$ and a burst duration of $1.7 \mathrm{~ms}$ [137]. Long closed times are more difficult to measure as most patches contain a number of channels. Kinetic analysis of the cleanest recordings from patches with relatively low channel activity suggest the existence of only one long closed state but with a highly variable closed time of between 2 and $30 \mathrm{~ms}$ [137]. The mean single channel conductance was initially estimated at about $14 \mathrm{pS}$ [17], but it was subsequently discovered that this is dependent upon extracellular magnesium. Early measurements were made presence of $4 \mathrm{mM}$ extracellular (pipette) $\mathrm{Mg}^{2+}$. In the absence of extracellular $\mathrm{Mg}^{2+}$, mean single channel amplitude is about $28 \mathrm{pS}$ [137]. Whilst these biophysical properties were broadly consistent with a TASK-like channel, it was notable that single channel conductance, and its dependence upon extracellular $\mathrm{Mg}^{2+}$, was distinct from that of both TASK1 and TASK3. This led to the suggestion that the native TASK-like channel might be a heterodimer [137] as TASK1 and TASK3 had been reported to heterodimerise in some expression systems [28].

Subsequent analysis of single channel records in rat type 1 cells, with particular emphasis on single channel conductance and its sensitivity to extracellular magnesium, led Kim et al. to propose that type 1 cells contain a mixture of homomeric TASK1 and TASK3 channels together with a third channel type that was intermediate in size having a conductance equivalent to that of a TASK1-TASK3 concatameric channel [56]. It was proposed that this third, and most abundant, form of channel activity arose from a native heterodimeric assembly of both TASK1 and TASK3 subunits [56]. Further studies in transgenic mice have confirmed that the predominant form of channel activity in type 1 cells is indeed a TASK1/TASK3 heterodimer [129]. In type 1 cells from wild-type mice, the principal form of single channel activity in cell-attached 




Fig. 1 Ion channels and electrical signalling in type 1 cells. Putative summary model of key ion channels/currents in rat type 1 cells. Background channels and currents setting the resting potential include TASK, predominantly TASK1/TASK3 heterodimers plus some contribution from TASK1 and TASK3 homodimers; Na-leak, an uncharacterised background $\mathrm{Na}^{+}$-leak conductance; and $\mathbf{N a} / \mathbf{K}$ ATPase, an $\mathrm{Na} / \mathrm{K}$ pump current presumed to be present in order to maintain intracellular $\mathrm{Na}^{+}$ homeostasis. Voltage-gated channels mediating electrical activity (action potentials) in the rat type 1 cell include $\mathbf{C a}_{\mathbf{v}}$, voltage-gated calcium channels including L-type and N-type channels; $\mathbf{K}_{\mathbf{V}}$, voltagegated, delayed rectifier type, potassium channels (other species may also have voltage gated $\mathrm{Na}^{+}$channels). Calcium-activated channels include $\mathbf{B K}_{\mathbf{C a}}$, a large conductance calcium-activated potassium channel (note this channel is also voltage sensitive) and $\mathbf{C a t}_{\mathbf{C a}}$, a calcium-activated cation channel permeable to $\mathrm{Na}^{+}$ions. Signalling pathway for both hypoxia and acidosis involves inhibition of TASK channels (all three forms) and maxi- $\mathrm{K}^{+}$channels. Inhibition of TASK leads to membrane depolarisation, followed by activation of voltage-gated $\mathrm{Ca}^{+}$channels generating $\mathrm{Ca}^{2+}$ influx and upstroke of action potentials; $\mathrm{K}_{\mathrm{V}}$ is assumed to mediate action potential repolarisation. The resulting rise in $\left[\mathrm{Ca}^{2+}\right]_{i}$ not only promotes neurosecretion but also activates a non-selective cation channel which reinforces the depolarising effect of TASK channel inhibition. $\mathrm{Ca}^{2+}$-dependent activation of maxi-K channels would be expected to repolarise the type 1 cell and limit $\mathrm{Ca}^{2+}$ influx were it not also inhibited by hypoxia/acidosis [102, 103]. Channels in red mediate inward (depolarising) current, those in blue mediate outward (repolarising/hyperpolarising) current

In a small number of patches from normal mouse type 1 cells, a TASK1-like channel was also observed, suggesting that both homomeric TASK1 channels and heteromeric TASK1/ TASK 3 are present in mouse type 1 cells as is observed in rat type 1 cells $[56,129]$. The main form of channel activity present however is the TASK1/TASK3 heteromultimer (in both species) which suggests that heterodimerisation is preferred to homodimerisation. Indeed, it was noted that the prevalence of heteromeric TASK1/TASK3 channels in normal type 1 cells was much greater than that of the homomeric TASK1 and TASK3 forms seen in the single knockout animals [129]. This suggests that heteromeric channels might be more readily formed or trafficked to the membrane, or more stable, or more active than homomeric channels. 


\section{Consequences of constitutive genetic deletion of Task1 and Task3}

Deletion/knockout (KO) of Task3 in mice has been reported to have no effect upon the ventilatory response to hypoxia. In contrast, deletion of Taskl blunted the ventilatory response to hypoxia and depressed the chemoafferent (carotid sinus nerve) response to hypoxia in vitro [127]. Double knockout (DKO) of both Task1 and Task3 similarly reduced both ventilatory and chemoreceptor nerve responses to hypoxia but did not completely abolish them [127]. In studies conducted on type 1 cells in vitro, however, constitutive deletion of Task3 and/or Task 1 appeared to have little effect upon either calcium signalling or neurosecretion in response to hypoxia (a small increase in basal neurosecretion was noted in the DKO) $[17$, 92].

Given the importance of TASK1/TASK3 in setting resting membrane potential, the loss of either or both of Taskl and Task3 would be expected to result in a sustained depolarisation of type 1 cells and an increase in resting $\left[\mathrm{Ca}^{2+}\right]_{\mathrm{i}}$. Resting $\left[\mathrm{Ca}^{2+}\right]_{\mathrm{i}}$ was however similar in all knockout animals [17], and resting membrane potential was only slightly depolarised in DKO (Task1 ${ }^{-/} ;$Task $^{-/-}$) mice [92]. This indicates that the loss of Task 1 and/or Task 3 must be largely compensated for in some way. Since $\mathrm{K}^{+}$channel activity at negative membrane potentials was much reduced in all of these knockouts [17], and resting membrane conductance was much reduced in the DKO [92], the upregulation of another type of background potassium channel would seem not to be the principal means of compensation. Other possibilities include the downregulation of voltage-gated $\mathrm{Ca}^{2+}$ currents [92] which might help stabilise resting membrane potential and/or changes in the magnitude of other background currents, e.g. the inward (leak) $\mathrm{Na}^{+}$current.

Irrespective of the means by which type 1 cells from KO and DKO animals avoid sustained depolarisation, what is more interesting is that they retain chemosensitivity to hypoxia. In single $\mathrm{KO}$ animals, this can be explained by the fact that the homomeric forms of TASK 3 and TASK1 are also oxygen sensitive. In the case of the double knockout, however, it is clear that neither TASK1 nor TASK3 can be involved. Calcium-activated potassium channels $\left(\mathrm{BK}_{\mathrm{Ca}}\right)$ and some voltage-activated potassium channels $\left(\mathrm{K}_{\mathrm{V}}\right)$ also display oxygen sensitivity in type 1 cells $[73,74,102,104,107,143]$, but they tend to be already closed at potentials negative to $-30 \mathrm{mV}[92,107] . \mathrm{BK}_{\mathrm{Ca}}$ and/or $\mathrm{K}_{\mathrm{V}}$ channels would thus seem unlikely to be able to account for excitation of DKO type 1 cells. The implication of this data therefore is that type 1 cells must possess other, as yet unknown, oxygen-sensitive ion channels. Task $1^{-/}$; Task $^{-/-}$mice could therefore be a useful tool to aid the discovery of novel oxygen-sensitive channels. It should be noted however that the use of constitutive knockouts to infer the functional role of specific ion channels in normal animals is likely to be fraught with uncertainty. Naturally occurring variations in gene transcription from cell to cell combined with a mutation that has the potential to affect cell viability could well lead to the selective survival of an atypical cell population.

\section{Regulation of type 1 cell TASK channels by acidosis}

Peripheral chemoreceptors are important sensors of blood acid base chemistry. Whilst they may contribute little more than $20-30 \%$ of the respiratory drive in response to hypercapnic acidosis, the rest being mediated by central chemoreceptors, they are able to respond to an acute hypercapnia more rapidly than the central chemoreceptors. They are also able to detect metabolic acidosis (a fall in blood $\mathrm{pH}$ at constant $\mathrm{CO}_{2}$, e.g. as in diabetic ketoacidosis) which central chemoreceptors cannot. They can therefore provide a respiratory compensation for metabolic acid base disturbances. The transduction of acid stimuli, both hypercapnic and metabolic acidosis, involves the inhibition of background (TASK1/3) $\mathrm{K}^{+}$currents much as for hypoxia $[15,17]$. These channels are so named for their acid sensitivity with TASK1 being slightly more sensitive within the physiological range $(p K=7.2-7.3)$ than TASK3 ( $p K=6.0$ 6.7) $[36,54,55,69,79,112]$. The acid sensitivity of TASK 1 and TASK3 is largely attributable to the protonation of a histidine residue in the large extracellular loop/helical cap region $[55,71,86,112]$. Outside-out patch recordings of TASK-like channels in type 1 cells also show an external $\mathrm{pH}$ sensitivity with channel inhibition at $\mathrm{pH}$ less than 7.3 [56].

There is also evidence that the carotid body and type 1 cells can be excited by isohydric hypercapnia [13, 46, 65, 147]. Since this stimulus does not present an external acidosis, there must be another sensory mechanism probably linked to the intracellular acidosis caused by $\mathrm{CO}_{2}$ influx. This could be a direct effect of internal $\mathrm{pH}$ on TASK channels, or it might involve the metabolic signalling pathway (see below) since phosphofructokinase, a key enzyme and control point in glycolysis, is highly $\mathrm{pH}$ sensitive [128]. The effects of intracellular acidosis on TASK $1 / 3$ in these cells remain to be determined.

\section{Effects of hypoxia on TASK channels in type 1 cells}

As noted above, the primary effect of hypoxia is to reduce background $\mathrm{K}^{+}$currents in the type 1 cell, thus evoking membrane depolarisation, neurosecretion and excitation of the carotid sinus nerve. Studies conducted at the single channel level suggest that hypoxia reduces channel open probability mainly by stabilising the long closed state $[17,137]$. Studies in knockout mice have further demonstrated that hypoxia can inhibit all three forms of these channels, i.e. TASK1/TASK3 
heterodimers as well as homodimers of both TASK1 and TASK3 [129]. Although the effects of hypoxia on TASK3 appeared to be less dramatic than its effects on TASK1 and TASK1/TASK3, this data nonetheless indicates that the oxygen sensing pathway, whatever it may be, can couple to either TASK channel subunit.

Oxygen sensitivity in both TASK1 and the related channel TREK-1 has also been reported in heterologous expression systems (HEK293) [67, 81]. We however have never been able to replicate these findings $[10,11]$. It may be that other cells lack the appropriate oxygen sensing pathway, or that some additional channel subunit is required, or that uncontrolled over expression of these channels dilutes/titrates out some other important cofactor. Whatever the reason for this failure, it has been a major impediment to the investigation of putative oxygen sensing pathways regulating these channels. Studies conducted in type 1 cells have however provided us with some interesting insights.

The first, and most important, observation is that oxygen sensing is not seen in excised patch recordings [17]. Nor do we see hypoxic inhibition of background $\mathrm{K}^{+}$current in conventional whole cell recordings. Indeed, these experimental techniques result in very rapid and extensive rundown in $\mathrm{K}^{+}$ current/channel activity (an approximate $90 \%$ reduction within 10-20 s) [137]. This demonstrates that cellular constituents are essential to maintain normal levels of channel activity under normoxic conditions and to confer oxygen sensitivity on the channel. Thus, although often colloquially referred to as an "oxygen-sensitive" ion channel, there is no evidence yet that TASK channels are directly oxygen sensitive.

One of the cellular constituents that is likely to play a key role in maintaining TASK channel activity is MgATP. Studies using inside-out patches have shown that, post rundown, $5 \mathrm{mM} \mathrm{MgATP}$ can increase channel activity by around fivefold [132]. Whilst this is not sufficient to fully restore channel activity to the levels seen in cell-attached patches, it is nonetheless likely to be a highly significant influence on channel activity. This effect requires the magnesium chelated form of ATP and can be mimicked by other Mg nucleotides including MgADP and MgGTP but requires millimolar levels of nucleotides, so that significant activation by MgADP or MgGTP is not anticipated in the intact cell. The $K_{m}$ for channel activation by MgATP, $2.3 \mathrm{mM}$, on the other hand, is within the normal physiological range for cytoplasmic MgATP concentration [132]. This observation is of particular relevance to one of the oldest theories of chemoreception, the metabolic hypothesis.

\section{Mechanisms of oxygen sensing in TASK channels: the metabolic hypothesis}

The metabolic hypothesis posits that oxygen is sensed through changes in mitochondrial energy metabolism. This is supported by a number of key observations. The first is that inhibitors of mitochondrial respiration are all potent chemostimulants [3, $48,87,117]$. The second is that the oxygen sensitivity of mitochondrial function in type 1 cells appears to be specifically adapted to the role of oxygen sensing [33, 34, 83, 84]. This latter observation has been particularly contentious over the years, but a recent study confirms that the apparent $K_{m}$ for oxygen utilisation by cytochrome oxidase is extraordinarily high in these cells, possibly uniquely so [12]. Early observations that mitochondrial inhibitors excite chemosensory nerves and increase ventilation have proven remarkably robust and are supported by more recent studies, demonstrating that a wide variety of metabolic inhibitors depolarise type 1 cells and evoke a rise in intracellular calcium [16, 140]. For all inhibitors studied thus far, excitation results from the inhibition of background/TASK channel current. Studies in TASK KO mice have further shown that metabolic inhibitors modulate all three forms of TASK channel in these cells (i.e., TASK1, TASK3 and TASK1/TASK3 heterodimers), see Fig. 2 [129]. This data provides compelling evidence that a metabolic sensing/signalling pathway couples to TASK channels in type 1 cells. It has further been observed that the effects of metabolic inhibitors and hypoxia upon background (TASK) $\mathrm{K}^{+}$current are mutually exclusive [140], suggesting that both signalling pathways converge at the level of mitochondrial metabolism.

Thus, the metabolic hypothesis of oxygen sensing is almost complete. Hypoxia inhibits mitochondrial electron transport [12]; this leads to a fall in cytosolic MgATP (which has been indirectly observed using Mg-sensitive dyes, see [132]), and this leads to TASK channel inhibition. Leaving aside the issue of why type 1 cell mitochondria behave thus, there is another, channel centric, conundrum. Whilst MgATP may stimulate the native TASK1/TASK3 heterodimers in type 1 cells, there is no recognisable nucleotide binding site in either channels primary sequence. Moreover, there have been no reports of MgATP sensitivity for cloned TASK1 or TASK3. It may therefore be that another intermediary, possibly an accessory subunit to the channel, is required to confer MgATP sensitivity.

\section{Mechanisms of oxygen sensing in TASK channels: the AMP kinase hypothesis}

The AMP kinase (AMPK) hypothesis of oxygen sensing is, in essence, another variant of the metabolic hypothesis. It proposes that various potassium channels (including TASK channels) are regulated by phosphorylation via AMP-activated kinase. AMPK is a well-known metabolic energy sensor which pays a key role in coordinating metabolism and cellular energy demand in other cell types. The basic model is that when ATP demand begins to exceed supply, there is a net conversion of ATP to ADP, followed by the conversion of ADP to AMP. AMP then activates the kinase by both displacing ATP which is normally bound to the AMP kinase and in the process 


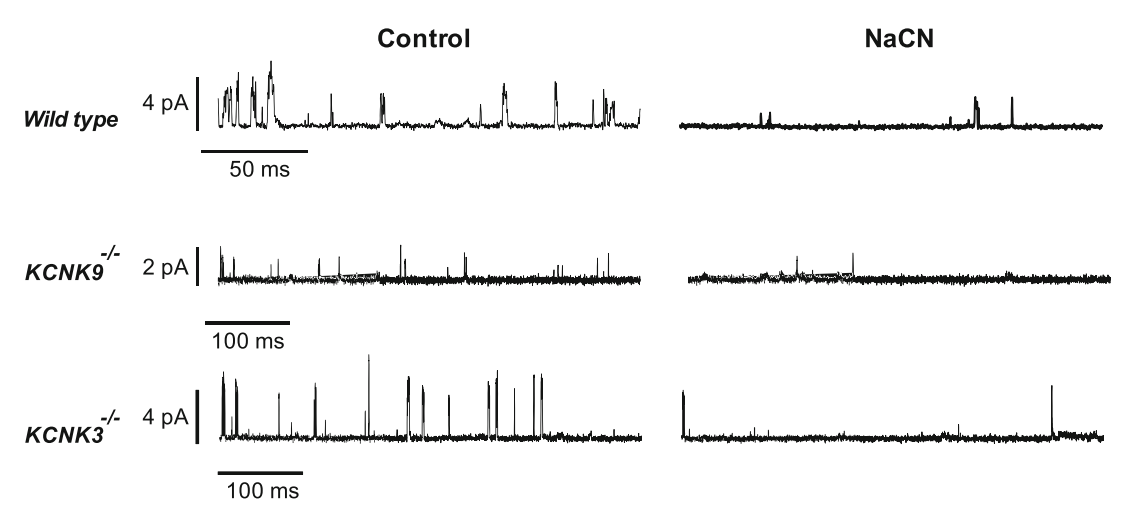

Fig. 2 Metabolic regulation of TASK channels. Effects of cyanide $(2 \mathrm{mM})$ on TASK channel activity in cell-attached patches from mouse type 1 cells. Wild-type cells show primarily TASK1/TASK3 heterodimer channel activity. $K C N K 9^{-/}$cells (Task3 KO) show TASK1-like activity.

making AMPK susceptible to activation by phosphorylation via an upstream kinase, e.g. LKB1 (see [47]). Hence, there is an implied failure of type 1 cell metabolism to maintain cellular ATP levels during hypoxia.

Initial evidence for a role of AMPK in oxygen sensing included the observations that 1) AICAR, an activator of AMPK,stimulated both isolated chemoreceptors and type 1 cells; and 2) that compound C, an inhibitor of AMPK, attenuated the excitatory effects of both AICAR and hypoxia [39, 141]. This was followed by conflicting evidence as to the ability of AMPK to phosphorylate and/or inhibit TASK channels. AICAR was reported to inhibitTASK3 but not TASK1 in H293 cells by Dallas et al. [30]. In contrast, Kréneisz et al. reported that AICAR had no effect upon TASK1, TASK3 or the TASK1/3 concatamer in HEK293 [63]. A more recent study has also failed to find any effect of the AMPK activators AICAR or A769662 on either TASK channel activity or $\mathrm{Ca}^{2+}$ signalling in isolated rat type 1 cells or any effect of compound C upon TASK channel inhibition by hypoxia [58]. We have obtained similar results in respect of the lack of effects of AICAR and A769662 on $\mathrm{Ca}^{2+}$ signalling in type 1 cells (Buckler unpublished). The role of AMPK in regulating TASK channels in the type 1 cell is therefore currently in doubt.

\section{Mechanisms of oxygen sensing in TASK channels: role of hydrogen sulfide and carbon monoxide}

There has recently been much interest in the role of the putative gaseous signalling molecules $\mathrm{H}_{2} \mathrm{~S}$ and $\mathrm{CO}$ in oxygen sensing both in the carotid body and in vascular smooth muscle. The reader is directed to a number of recent reviews for the relevant background $[91,110]$. Suffice to say that the effects of exogenous sulfide have been tested in the carotid body and isolated type 1 cells, and it appears to mimic the effects of hypoxia in all major respects including the depolarisation of type 1 cells through the inhibition of
$\mathrm{KCNK}^{--}$cells (Task1 KO) show TASK3-like activity. Note that all forms of TASK channel activity are suppressed by cyanide. Similar effects were also seen for hypoxia and the mitochondrial uncoupler FCCP, see [129]

background $\mathrm{K}^{+}$currents and TASK channel activity $[9,105]$. The effects of exogenous $\mathrm{H}_{2} \mathrm{~S}$ are manifest at micromolar levels, however, which are sufficient to also inhibit mitochondrial metabolism (as measured in the type 1 cell). Moreover, $\mathrm{H}_{2} \mathrm{~S}$ had no additional effect upon TASK channel activity in the presence of cyanide [9]. This suggests that modulation of TASK channels by $\mathrm{H}_{2} \mathrm{~S}$ is simply another manifestation of metabolic sensing in type 1 cells. A similar argument may be applied to the effects of carbon monoxide. High levels of $\mathrm{CO}$ excite the carotid body, depolarise type 1 cells and inhibit the background $\mathrm{K}^{+}$conductance [4]. At these levels, however, $\mathrm{CO}$ will also inhibit cytochrome oxidase, suggesting that the actions of $\mathrm{CO}$ on background (TASK) current is again most likely to be due to metabolic signalling.

\section{Mechanisms of oxygen sensing in TASK channels: reactive oxygen species}

Reactive oxygen species have also been implicated in acute oxygen sensing, most notably in the pulmonary vasculature (see [123] for a review) which also expresses TASK-like Kcurrents [90]. Kim et al. [96] have investigated the effects of hydrogen peroxide on TASK1, TASK 3 and the TASK1/ TASK 3 concatamer expressed in HeLa cells, as well as the TASK channels in type 1 cells. Peroxide was found to evoke an irreversible stimulation of all of these channels in the excised patch configuration but only at exceptionally high concentrations $(\geq 16 \mathrm{mM})$. This suggests that $\mathrm{H}_{2} \mathrm{O}_{2}$ at least is unlikely to directly modulate TASK channels physiologically.

\section{Neurotransmitter and autocrine regulation of TASK channels in type 1 cells}

The carotid body has a rich diversity of neurotransmitters and neurotransmitter receptors which provide for a complex 
regulation by neurocrine, autocrine and paracrine signalling events involving type 1 cells, nerve endings and type 2 cells. There have, as yet, been relatively few studies of the impact of such signalling pathways on TASK channels in type 1 cells although this would be a prime target for regulating chemoreceptor excitability. Three substances of likely physiological significance have thus far been identified that can regulate the background TASK channels in type 1 cells.

Adenosine is a powerful stimulant of the carotid body [78, $115,131]$ and is released in response to hypoxia. Extracellular adenosine can be derived from two sources: (1) the breakdown of ATP that has been released as a neurotransmitter by the type 1 cell and (2) adenosine efflux from the cell via transporters in response to increased adenosine generation following cytosolic ATP breakdown [24]. Adenosine causes a marked increase in intracellular calcium and membrane depolarisation in isolated type 1 cells, an effect that was mimicked by the TASK1 inhibitor anandamide (see below). Prior exposure to anandamide prevented any further effect of adenosine from which it was concluded that the effects of adenosine were likely to be mediated by inhibition of TASK channels [142]. Although no direct studies of the effects of adenosine on TASK channels have yet been reported in the carotid body, the second messenger pathways implicated, activation of $A_{2 A}$ receptors $G_{s}$ increase in cAMP and protein kinase $A$ (PKA) activation, have also been implicated in the modulation of TASK current by GABA. In contrast to the proposed effects of adenosine, GABA is reported to activate TASK current in type 1 cells through activation of $\mathrm{GABA}_{\mathrm{B}}$ receptors $\mathrm{G}_{\mathrm{i}}$ and inhibition of adenylate cyclase and PKA activity [40].

Serotonin is another neurotransmitter released from type 1 cells [146]. Serotonin is reported to inhibit the resting Kconductance in type 1 cells leading to depolarisation and cell excitation. These effects are thought to be mediated via $5-\mathrm{HT}_{2}$ receptors and activation of another classical signalling pathway protein kinase $\mathrm{C}$ [145].

\section{Pharmacological modulation of TASK channels in type 1 cells}

A number of substances have been observed to inhibit TASK channels in the type 1 cell. Of these, anandamide/ methanandamide are probably among the more selective. Anandamide was originally reported to inhibit TASK1 in heterologous expression systems [75] but was subsequently found to also inhibit both TASK 3 and the TASK $1 / 3$ concatamer $[56,133]$. It has been observed to inhibit both background currents [138] and TASK channels in type 1 cells [56]. Ruthenium red, an inhibitor of TASK3 (but not of TASK1, TASK1/3 concatamers or TASK1/TASK3 heterodimers) $[52,60]$ has only a small $(20 \%)$ effect upon TASK channel activity in type 1 cells, supporting the view that
TASK 3 contributes little to the background TASK-like current overall [56]. Other less selective inhibitors of the TASK-like current in type 1 cells include zinc, barium and quinidine [17]. The effects of recently described selective inhibitors of TASK1 and TASK3, e.g. PK-THPP, A1899 and A293 [7, $42,82]$, on type 1 cell TASK channels have not yet been reported. Some of these agents (PK-THPP and A1899) have however been found to act as respiratory stimulants [26]. This is consistent with inhibition of type 1 cell TASK channels and peripheral chemoreceptor excitation. Conversely, the widely used respiratory stimulant doxapram, which is known to excite the carotid body $[85,88]$, has been found to inhibit cloned TASK 1, TASK 3 and the TASK $1 / 3$ heterodimer [27]. It is therefore anticipated that doxapram will also directly excite the type 1 cell through the inhibition of TASK channels although this has yet to be formally demonstrated. There is little other known pharmacology for TASK in type 1 cells save for the observation that it is strongly activated by the gaseous anaesthetic halothane [17] and weakly activated by isoflurane [95]. The effects of these anaesthetics on channel activity mirror their ability to blunt the acute hypoxic ventilatory response and antagonise type 1 cell responses to hypoxia $[93,94]$. Anaesthetic activation of TASK channels is thought to involve two regions of the molecule: a potential binding site located in/near the cytoplasmic end of the second transmembrane domain and another region at the beginning of the c-terminal domain, referred to as the halothane response element, which is important in transducing the effects of anaesthetic $[2,124]$.

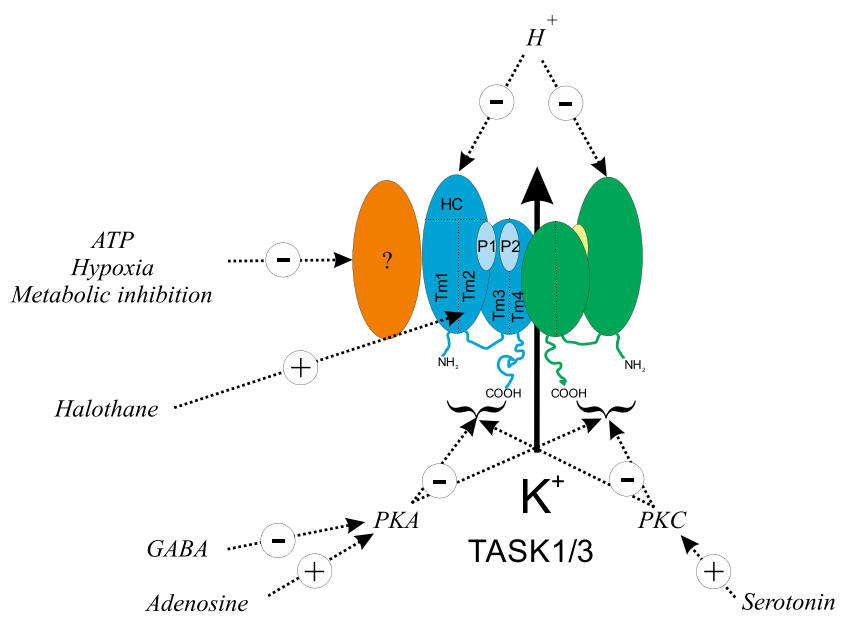

Fig. 3 Schematic of TASK channel regulation in type 1 cells of the carotid body. Cartoon depicts key regions of the TASK channels including transmembrane spanning domains $\mathrm{Tm} 1, \mathrm{Tm} 2, \mathrm{Tm} 3$ and $\mathrm{Tm} 4$, pore loops $\mathrm{P} 1+\mathrm{P} 2$, the extracellular helical cap between $\mathrm{Tm} 1$ and $\mathrm{P} 1$, and $\mathrm{N}$ - and C-terminal domains. Hypoxia/metabolic inhibition/cytosolic ATP signalling is presumed to involve some unknown intermediary, e.g. an accessory subunit (?), see text. Modulation by extracellular acidosis probably involves a histidine residue (H98) in the helical cap region (HC). Gaseous inhalational anaesthetics, e.g. halothane, may bind to a region in/near the C-terminal end of the M2 segment [2]. Site of action of the protein kinases PKA and PKC is unknown but is assumed to involve cytoplasmic domains 


\section{Future perspectives}

One of the most pressing problems is in identifying the signalling mechanisms involved in mediating the effects of hypoxia, metabolic inhibition and cytosolic ATP. Is ATP the only signalling molecule involved in oxygen/metabolic signalling? It certainly has a substantive effect upon TASK channel activity in the type 1 cell, but so to do other unknown cytosolic constituents judging by the degree of channel rundown following patch excision. $\mathrm{PIP}_{2}$ depletion is a common cause of channel rundown and has been implicated in TASK channel regulation in some cells/expression systems [22, 70] but not others [23, 68]. The effects of $\mathrm{PIP}_{2}$ on type 1 cell TASK channels are unknown. Beyond this, it is difficult to know where to start, but metabolic profiling of other tissues subject to hypoxia or mitochondrial poisons may provide clues.

Another general area of investigation is in the many other ways in which TASK channel activity could be influenced (see Fig. 3). Given their role in setting the type 1 cells resting membrane potential, TASK channels are likely to be highly effective targets for processes regulating the excitability of chemoreceptors overall. This has a number of implications, e.g. (1) short-term neuromodulation of chemoreceptor function by neurotransmitters, (2) long-term plasticity of chemoreceptor responses, (3) carotid body dysfunction (pathology), (4) therapeutic intervention, and (5) unwanted pharmacological side effects.

Neuromodulation A role for TASK channels in the neuromodulation of type 1 cell excitability has already been discussed with respect to adenosine, GABA and serotonin. There are however many other important neurotransmitters present in the carotid body including acetylcholine, dopamine and NO [89]. The effects of these pathways on TASK channel activity are all awaiting investigation. It is notable that TASK channels are strongly regulated by $\mathrm{G}_{\mathrm{q}}$-coupled receptors in other tissues [22, 29, 37, 76, 80, 118, 125], possibly through increase in diacylglycerol [136] and/or by direct interaction with $\mathrm{G}_{\mathrm{q}} \alpha$-subunits [23]. Possible direct effects of $\mathrm{G}_{\mathrm{q}} \alpha$ subunits and diacylglycerol have not yet been studied in the type 1 cell.

Plasticity of chemoreceptor responses There are two physiological processes involving chemoreceptor plasticity. One is in the resetting of chemoreceptor oxygen sensitivity in the early postnatal period. This has been attributed to changes in calcium signalling in type 1 cells [122] and is known to be accompanied by changes in expression patterns and oxygen sensitivity of TASK channels in the type 1 cell $[57,59]$. The second form of plasticity is in ventilatory acclimatisation to hypoxia. This is a classical adaptation to life at altitude in which chemoreceptor response to hypoxia is augmented over a period of hours to days [50, 51, 64]. It is likely to be a multifactorial event probably involving short-term plasticity and longer term hyperplasia of type 1 cells which may be driven by oxygen-sensitive gene transcription and/or as a consequence of local signalling [6, 61, 66, 98, 109, 119]. The role of TASK channels in these processes awaits investigation.

Carotid body dysfunction A number of clinical conditions have been associated with chemoreceptor dysfunction including sleep apnoea, sympathetic over activity in heart failure and hypertension $[1,77,99,100,111,116]$. These are all complex phenomena in which the role of the carotid body is still at an early stage of investigation. The availability of drugs or other interventions that could modulate TASK channel activity (and thus chemoreceptor excitability) could prove to be of particular value in evaluating the role of chemoreceptor excitation in these situations and, possibly in the long term, in their treatment.

Pharmacological side effects Depression of ventilation and inhibition of the ventilatory response to hypoxia is a well-known side effect of a number of general anaesthetic agents which can result in hypoxemia, a significant cause of postoperative morbidity and mortality [44, 62, 134]. A better understanding of how such agents work, particularly their effects on TASK channels, could lead to improvements in anaesthetic design. Moreover, the development of TASK channel inhibitors may provide for a new generation of respiratory stimulants [26] to combat the effects of anaesthetic induced respiratory depression. In summary, there is still a great deal to be learnt about the functional role and regulation of TASK channels in arterial chemoreceptors and their potential value as targets for therapeutic intervention.

Acknowledgments This work was supported in part by grants from the BHF (PG/08/086/25849) and the MRC (project grant G101134). I am grateful for the assistance of Dr. Philip Turner for reading and commenting upon earlier versions of this manuscript and in the preparation of Fig. 2.

Open Access This article is distributed under the terms of the Creative Commons Attribution License which permits any use, distribution, and reproduction in any medium, provided the original author(s) and the source are credited.

\section{References}

1. Abdala AP, McBryde FD, Marina N, Hendy EB, Engelman ZJ, Fudim M, Sobotka PA, Gourine AV, Paton JF (2012) Hypertension is critically dependent on the carotid body input in the spontaneously hypertensive rat. J Physiol 590:4269-4277 
2. Andres-Enguix I, Caley A, Yustos R, Schumacher MA, Spanu PD, Dickinson R, Maze M, Franks NP (2007) Determinants of the anesthetic sensitivity of two-pore domain acid-sensitive potassium channels: molecular cloning of an anesthetic-activated potassium channel from Lymnaea stagnalis. J Biol Chem 282:20977-20990

3. Anichkov S, Belen'kii M (1963) Pharmacology of the carotid body chemoreceptors. Pergamon, Oxford

4. Barbe C, Al-Hashem F, Conway AF, Dubuis E, Vandier C, Kumar P (2002) A possible dual site of action for carbon monoxide-mediated chemoexcitation in the rat carotid body. J Physiol 543:933-945

5. Bin Jaliah I, Maskell PD, Kumar P (2004) Indirect sensing of insulin-induced hypoglycaemia by the carotid body in the rat. $\mathrm{J}$ Physiol 556:255-266

6. Bishop T, Talbot NP, Turner PJ, Nicholls LG, Pascual A, Hodson EJ, Douglas G, Fielding JW, Smith TG, Demetriades M, Schofield CJ, Robbins PA, Pugh CW, Buckler KJ, Ratcliffe PJ (2013) Carotid body hyperplasia and enhanced ventilatory responses to hypoxia in mice with heterozygous deficiency of PHD2. J Physiol 591:35653577

7. Bittner S, Bauer MA, Ehling P, Bobak N, Breuer J, Herrmann AM, Golfels M, Wiendl H, Budde T, Meuth SG (2012) The TASK1 channel inhibitor A293 shows efficacy in a mouse model of multiple sclerosis. Exp Neurol 238:149-155

8. Buckler KJ (1997) A novel oxygen-sensitive potassium current in rat carotid body type I cells. J Physiol 498:649-662

9. Buckler KJ (2012) Effects of exogenous hydrogen sulphide on calcium signalling, background (TASK) $\mathrm{K}$ channel activity and mitochondrial function in chemoreceptor cells. Pflugers Arch 463:743-754

10. Buckler K, Honore E (2004) Molecular strategies for studying oxygen-sensitive K+ channels. Methods Enzymol 381:233-256

11. Buckler KJ, Honore E (2005) The lipid-activated two-pore domain $\mathrm{K}+$ channel TREK-1 is resistant to hypoxia: implication for ischaemic neuroprotection. J Physiol 562:213-222

12. Buckler KJ, Turner PJ (2013) Oxygen sensitivity of mitochondrial function in rat arterial chemoreceptor cells. J Physiol 591:35493563

13. Buckler KJ, Vaughan Jones RD (1993) Effects of acidic stimuli on intracellular calcium in isolated type I cells of the neonatal rat carotid body. Pflugers Arch 425:22-27

14. Buckler KJ, Vaughan Jones RD (1994) Effects of hypoxia on membrane potential and intracellular calcium in rat neonatal carotid body type I cells. J Physiol 476:423-428

15. Buckler KJ, Vaughan Jones RD (1994) Effects of hypercapnia on membrane potential and intracellular calcium in rat carotid body type I cells. J Physiol 478:157-171

16. Buckler KJ, Vaughan-Jones RD (1998) Effects of mitochondrial uncouplers on intracellular calcium, $\mathrm{pH}$ and membrane potential in rat carotid body type I cells. J Physiol 513(Pt 3):819-833

17. Buckler KJ, Williams BA, Honore E (2000) An oxygen-, acid- and anaesthetic-sensitive TASK-like background potassium channel in rat arterial chemoreceptor cells. J Physiol 525(Pt 1):135-142

18. Buttigieg J, Nurse CA (2004) Detection of hypoxia-evoked ATP release from chemoreceptor cells of the rat carotid body. Biochem Biophys Res Commun 322:82-87

19. Carpenter E, Peers C (1997) Swelling- and cAMP-activated Clcurrents in isolated rat carotid body type I cells. J Physiol 503: 497-511

20. Carpenter E, Peers C (2001) A standing $\mathrm{Na}+$ conductance in rat carotid body type I cells. Neuroreport 12:1421-1425

21. Carpenter E, Wyatt CN, Hatton CJ, Bee D, Peers C (1996) Ca2+ channel currents in type I carotid body cells from normoxic and chronically hypoxic rats. Adv Exp Med Biol 410:105-108

22. Chemin J, Girard C, Duprat F, Lesage F, Romey G, Lazdunski M (2003) Mechanisms underlying excitatory effects of group I metabotropic glutamate receptors via inhibition of $2 \mathrm{P}$ domain $\mathrm{K}+$ channels. EMBO J 22:5403-5411

23. Chen X, Talley EM, Patel N, Gomis A, McIntire WE, Dong B, Viana F, Garrison JC, Bayliss DA (2006) Inhibition of a background potassium channel by Gq protein alpha-subunits. Proc Natl Acad Sci U S A 103:3422-3427

24. Conde SV, Monteiro EC (2004) Hypoxia induces adenosine release from the rat carotid body. J Neurochem 89:1148-1156

25. Conde SV, Obeso A, Gonzalez C (2007) Low glucose effects on rat carotid body chemoreceptor cells' secretory responses and action potential frequency in the carotid sinus nerve. J Physiol 585:721730

26. Cotten JF (2013) TASK-1 (KCNK3) and TASK-3 (KCNK9) tandem pore potassium channel antagonists stimulate breathing in isoflurane-anesthetized rats. Anesth Analg 116:810-816

27. Cotten JF, Keshavaprasad B, Laster MJ, Eger EI 2nd, Yost CS (2006) The ventilatory stimulant doxapram inhibits TASK tandem pore $(\mathrm{K} 2 \mathrm{P})$ potassium channel function but does not affect minimum alveolar anesthetic concentration. Anesth Analg 102:779-785

28. Czirjak G, Enyedi P (2002) Formation of functional heterodimers between the TASK-1 and TASK-3 two-pore domain potassium channel subunits. J Biol Chem 277:5426-5432

29. Czirjak G, Fischer T, Spat A, Lesage F, Enyedi P (2000) TASK (TWIK-related acid-sensitive $\mathrm{K}+$ channel) is expressed in glomerulosa cells of rat adrenal cortex and inhibited by angiotensin II. Mol Endocrinol 14:863-874

30. Dallas ML, Scragg JL, Wyatt CN, Ross F, Hardie DG, Evans AM, Peers C (2009) Modulation of $\mathrm{O}(2)$ sensitive K (+) channels by AMP-activated protein kinase. Adv Exp Med Biol 648:57-63

31. Daly MB (1997) Peripheral arterial chemoreceptors and respiratorycardiovascular integration. Clarendon, Oxford

32. Dasso LL, Buckler KJ, Vaughan Jones RD (1997) Muscarinic and nicotinic receptors raise intracellular $\mathrm{Ca} 2+$ levels in rat carotid body type I cells. J Physiol 498:327-338

33. Duchen MR, Biscoe TJ (1992) Relative mitochondrial membrane potential and $[\mathrm{Ca} 2+] \mathrm{i}$ in type I cells isolated from the rabbit carotid body. J Physiol 450:33-61

34. Duchen MR, Biscoe TJ (1992) Mitochondrial function in type I cells isolated from rabbit arterial chemoreceptors. J Physiol 450: 13-31

35. Duchen MR, Caddy KW, Kirby GC, Patterson DL, Ponte J, Biscoe TJ (1988) Biophysical studies of the cellular elements of the rabbit carotid body. Neuroscience 26:291-311

36. Duprat F, Lesage F, Fink M, Reyes R, Heurteaux C, Lazdunski M (1997) TASK, a human background K+ channel to sense external $\mathrm{pH}$ variations near physiological $\mathrm{pH}$. EMBO J 16:5464-5471

37. Enyedi P, Czirjak G (2010) Molecular background of leak K+ currents: two-pore domain potassium channels. Physiol Rev 90:559 605

38. Esilva MJ, Lewis DL (1995) L- and N-type Ca2+ channels in adult rat carotid body chemoreceptor type I cells. J Physiol 489:689-699

39. Evans AM, Mustard KJ, Wyatt CN, Peers C, Dipp M, Kumar P, Kinnear NP, Hardie DG (2005) Does AMP-activated protein kinase couple inhibition of mitochondrial oxidative phosphorylation by hypoxia to calcium signaling in O2-sensing cells? J Biol Chem 280:41504-41511

40. Fearon IM, Zhang M, Vollmer C, Nurse CA (2003) GABA mediates autoreceptor feedback inhibition in the rat carotid body via presynaptic GABAB receptors and TASK-1. J Physiol 553:83-94

41. Fidone SJ, Gonzalez C (1986) Initiation and control of chemoreceptor activity in the carotid body. American Physiological Society, Bethesda

42. Flaherty DP, Simpson DS, Miller M, Maki BE, Zou B, Shi J, Wu M, McManus OB, Aube J, Li M, Golden JE (2014) Potent and selective inhibitors of the TASK-1 potassium channel through chemical 
optimization of a bis-amide scaffold. Bioorg Med Chem Lett 24: 3968-3973

43. Gallego-Martin T, Fernandez-Martinez S, Rigual R, Obeso A, Gonzalez C (2012) Effects of low glucose on carotid body chemoreceptor cell activity studied in cultures of intact organs and in dissociated cells. Am J Physiol Cell Physiol 302:C1128-C1140

44. Gelb AW, Knill RL (1978) Subanaesthetic halothane: its effect on regulation of ventilation and relevance to the recovery room. Can Anaesth Soc J 25:488-494

45. Gonzalez C, Almaraz L, Obeso A, Rigual R (1994) Carotid body chemoreceptors: from natural stimuli to sensory discharges. Physiol Rev 74:829-898

46. Gray BA (1968) Response of the perfused carotid body to changes in $\mathrm{pH}$ and $\mathrm{PCO}$. Respir Physiol 4:229-245

47. Hardie DG (2011) AMP-activated protein kinase: an energy sensor that regulates all aspects of cell function. Genes Dev 25:1895-1908

48. Heymans C, Bouckaert JJ, Dautrebande L (1931) Sinus carotidien et reflexes respiratoires: sensibilite des sinus carotidiens aux substances chimiques. Action stimulante respiratoire reflexe du sulfure de sodium, du cyanure de potassium, de la nicotine et de la lobeline. Arch Int Pharmacodyn Ther 40:54-91

49. Holmes AP, Turner PJ, Carter P, Leadbeater W, Ray CJ, Hauton D, Buckler KJ, Kumar P (2014) Glycogen metabolism protects against metabolic insult to preserve carotid body function during glucose deprivation. J Physiol. doi:10.1113/jphysiol.2014.276105

50. Howard LS, Robbins PA (1995) Ventilatory response to $8 \mathrm{~h}$ of isocapnic and poikilocapnic hypoxia in humans. J Appl Physiol (1985) 78:1092-1097

51. Howard LS, Robbins PA (1995) Alterations in respiratory control during $8 \mathrm{~h}$ of isocapnic and poikilocapnic hypoxia in humans. $\mathrm{J}$ Appl Physiol (1985) 78:1098-1107

52. Kang D, Han J, Talley EM, Bayliss DA, Kim D (2004) Functional expression of TASK-1/TASK-3 heteromers in cerebellar granule cells. J Physiol 554:64-77

53. Kang D, Wang J, Hogan JO, Vennekens R, Freichel M, White C, Kim D (2014) Increase in cytosolic Ca2+ produced by hypoxia and other depolarizing stimuli activates a non-selective cation channel in chemoreceptor cells of rat carotid body. J Physiol 592:1975-1992

54. Kim Y, Bang H, Kim D (1999) TBAK-1 and TASK-1, two-pore $\mathrm{K}(+)$ channel subunits: kinetic properties and expression in rat heart. Am J Physiol 277:H1669-H1678

55. Kim Y, Bang H, Kim D (2000) TASK-3, a new member of the tandem pore $\mathrm{K}(+)$ channel family. J Biol Chem 275:9340-9347

56. Kim D, Cavanaugh EJ, Kim I, Carroll JL (2009) Heteromeric TASK-1/TASK-3 is the major oxygen-sensitive background $\mathrm{K}+$ channel in rat carotid body glomus cells. J Physiol 587:2963-2975

57. Kim I, Donnelly DF, Carroll JL (2006) Modulation of gene expression in subfamilies of TASK $\mathrm{K}+$ channels by chronic hyperoxia exposure in rat carotid body. Adv Exp Med Biol 580:37-41, discussion 351-9

58. Kim D, Kang D, Martin EA, Kim I, Carroll JL (2014) Effects of modulators of AMP-activated protein kinase on TASK-1/3 and intracellular $\mathrm{Ca}(2+)$ concentration in rat carotid body glomus cells. Respir Physiol Neurobiol 195:19-26

59. Kim D, Papreck JR, Kim I, Donnelly DF, Carroll JL (2011) Changes in oxygen sensitivity of TASK in carotid body glomus cells during early postnatal development. Respir Physiol Neurobiol 177:228-3557

60. Kimura Y, Goto Y, Kimura H (2010) Hydrogen sulfide increases glutathione production and suppresses oxidative stress in mitochondria. Antioxid Redox Signal 12:1-13

61. Kline DD, Peng YJ, Manalo DJ, Semenza GL, Prabhakar NR (2002) Defective carotid body function and impaired ventilatory responses to chronic hypoxia in mice partially deficient for hypoxia-inducible factor 1 alpha. Proc Natl Acad Sci U S A 99: $821-826$
62. Knill RL, Gelb AW (1978) Ventilatory responses to hypoxia and hypercapnia during halothane sedation and anesthesia in man. Anesthesiology 49:244-251

63. Kreneisz O, Benoit JP, Bayliss DA, Mulkey DK (2009) AMPactivated protein kinase inhibits TREK channels. J Physiol 587: 5819-5830

64. Lahiri S, Edelman NH, Cherniack NS, Fishman AP (1981) Role of carotid chemoreflex in respiratory acclimatization to hypoxemia in goat and sheep. Respir Physiol 46:367-382

65. Lahiri S, Iturriaga R, Mokashi A, Botre F, Chugh D, Osanai S (1996) Adaptation to hypercapnia vs. intracellular $\mathrm{pH}$ in cat carotid body: responses in vitro. J Appl Physiol 80:1090-1099

66. Laidler P, Kay JM (1975) A quantitative morphological study of the carotid bodies of rats living at a simulated altitude of 4300 metres. $\mathrm{J}$ Pathol 117:183-191

67. Lewis A, Hartness ME, Chapman CG, Fearon IM, Meadows HJ, Peers C, Kemp PJ (2001) Recombinant hTASK1 is an O(2)-sensitive $\mathrm{K}(+)$ channel. Biochem Biophys Res Commun 285:1290-1294

68. Lindner M, Leitner MG, Halaszovich CR, Hammond GR, Oliver D (2011) Probing the regulation of TASK potassium channels by PI4, 5P(2) with switchable phosphoinositide phosphatases. J Physiol 589:3149-3162

69. Lopes CM, Gallagher PG, Buck ME, Butler MH, Goldstein SA (2000) Proton block and voltage gating are potassium-dependent in the cardiac leak channel Kcnk3. J Biol Chem 275:16969-16978

70. Lopes CM, Rohacs T, Czirjak G, Balla T, Enyedi P, Logothetis DE (2005) PIP2 hydrolysis underlies agonist-induced inhibition and regulates voltage gating of two-pore domain $\mathrm{K}+$ channels. J Physiol 564:117-129

71. Lopes CM, Zilberberg N, Goldstein SA (2001) Block of Kcnk3 by protons. Evidence that 2-P-domain potassium channel subunits function as homodimers. J Biol Chem 276:24449-24452

72. Lopez Lopez JR, De Luis DA, Gonzalez C (1993) Properties of a transient $\mathrm{K}+$ current in chemoreceptor cells of rabbit carotid body. $\mathrm{J}$ Physiol 460:15-32

73. Lopez Lopez J, Gonzalez C, Urena J, Lopez Barneo J (1989) Low pO2 selectively inhibits K channel activity in chemoreceptor cells of the mammalian carotid body. J Gen Physiol 93:1001-1015

74. Lopez Lopez JR, Gonzalez C, Perez Garcia MT (1997) Properties of ionic currents from isolated adult rat carotid body chemoreceptor cells: effect of hypoxia. J Physiol 499:429-441

75. Maingret F, Patel AJ, Lazdunski M, Honore E (2001) The endocannabinoid anandamide is a direct and selective blocker of the background $\mathrm{K}(+)$ channel TASK-1. EMBO J 20:47-54

76. Mathie A (2007) Neuronal two-pore-domain potassium channels and their regulation by $\mathrm{G}$ protein-coupled receptors. J Physiol 578:377-385

77. McBryde FD, Abdala AP, Hendy EB, Pijacka W, Marvar P, Moraes DJ, Sobotka PA, Paton JF (2013) The carotid body as a putative therapeutic target for the treatment of neurogenic hypertension. Nat Commun 4:2395

78. McQueen DS, Ribeiro JA (1983) On the specificity and type of receptor involved in carotid body chemoreceptor activation by adenosine in the cat. Br J Pharmacol 80:347-354

79. Meadows HJ, Randall AD (2001) Functional characterisation of human TASK-3, an acid-sensitive two-pore domain potassium channel. Neuropharmacology 40:551-559

80. Millar JA, Barratt L, Southan AP, Page KM, Fyffe RE, Robertson B, Mathie A (2000) A functional role for the two-pore domain potassium channel TASK-1 in cerebellar granule neurons. Proc Natl Acad Sci U S A 97:3614-3618

81. Miller P, Kemp PJ, Lewis A, Chapman CG, Meadows HJ, Peers C (2003) Acute hypoxia occludes hTREK-1 modulation: reevaluation of the potential role of tandem $\mathrm{P}$ domain $\mathrm{K}+$ channels in central neuroprotection. J Physiol 548:31-37 
82. Miller MR, Zou B, Shi J, Flaherty DP, Simpson DS, Yao T, Maki BE, Day VW, Douglas JT, Wu M, McManus OB, Golden JE, Aube J, Li M (2010) Development of a selective chemical inhibitor for the two-pore potassium channel, KCNK9 Probe Reports from the NIH Molecular Libraries Program. Bethesda

83. Mills E, Jobsis FF (1970) Simultaneous measurement of cytochrome a3 reduction and chemoreceptor afferent activity in the carotid body. Nature 225:1147-1149

84. Mills E, Jobsis FF (1972) Mitochondrial respiratory chain of carotid body and chemoreceptor response to changes in oxygen tension. $\mathrm{J}$ Neurophysiol 35:405-428

85. Mitchell RA, Herbert DA (1975) Potencies of doxapram and hypoxia in stimulating carotid-body chemoreceptors and ventilation in anesthetized cats. Anesthesiology 42:559-566

86. Morton MJ, O'Connell AD, Sivaprasadarao A, Hunter M (2003) Determinants of $\mathrm{pH}$ sensing in the two-pore domain $\mathrm{K}(+)$ channels TASK-1 and -2. Pflugers Arch 445:577-583

87. Mulligan E, Lahiri S, Storey BT (1981) Carotid body O2 chemoreception and mitochondrial oxidative phosphorylation. J Appl Physiol 51:438-446

88. Nishino T, Mokashi A, Lahiri S (1982) Stimulation of carotid chemoreceptors and ventilation by doxapram in the cat. J Appl Physiol 52:1261-1265

89. Nurse CA (2014) Synaptic and paracrine mechanisms at carotid body arterial chemoreceptors. J Physiol 592:3419-3426

90. Olschewski A, Li Y, Tang B, Hanze J, Eul B, Bohle RM, Wilhelm J, Morty RE, Brau ME, Weir EK, Kwapiszewska G, Klepetko W, Seeger W, Olschewski H (2006) Impact of TASK-1 in human pulmonary artery smooth muscle cells. Circ Res 98:1072-1080

91. Olson KR, Whitfield NL (2010) Hydrogen sulfide and oxygen sensing in the cardiovascular system. Antioxid Redox Signal 12:12191234

92. Ortega-Saenz P, Levitsky KL, Marcos-Almaraz MT, Bonilla-Henao V, Pascual A, Lopez-Barneo J (2010) Carotid body chemosensory responses in mice deficient of TASK channels. J Gen Physiol 135: 379-392

93. Pandit JJ (2002) The variable effect of low-dose volatile anaesthetics on the acute ventilatory response to hypoxia in humans: a quantitative review. Anaesthesia 57:632-643

94. Pandit JJ, Buckler KJ (2009) Differential effects of halothane and sevoflurane on hypoxia-induced intracellular calcium transients of neonatal rat carotid body type I cells. Br J Anaesth 103:701-710

95. Pandit JJ, Winter V, Bayliss R, Buckler KJ (2010) Differential effects of halothane and isoflurane on carotid body glomus cell intracellular $\mathrm{Ca} 2+$ and background $\mathrm{K}+$ channel responses to hypoxia. Adv Exp Med Biol 669:205-208

96. Papreck JR, Martin EA, Lazzarini P, Kang D, Kim D (2012) Modulation of K2P3.1 (TASK-1), K2P9.1 (TASK-3), and TASK1/3 heteromer by reactive oxygen species. Pflugers Arch 464:471480

97. Pardal R, Lopez Barneo J (2002) Low glucose-sensing cells in the carotid body. Nat Neurosci 5:197-198

98. Pardal R, Ortega-Saenz P, Duran R, Lopez-Barneo J (2007) Glialike stem cells sustain physiologic neurogenesis in the adult mammalian carotid body. Cell 131:364-377

99. Paton JF, Ratcliffe L, Hering D, Wolf J, Sobotka PA, Narkiewicz K (2013) Revelations about carotid body function through its pathological role in resistant hypertension. Curr Hypertens Rep 15:273280

100. Paton JF, Sobotka PA, Fudim M, Engelman ZJ, Hart EC, McBryde FD, Abdala AP, Marina N, Gourine AV, Lobo M, Patel N, Burchell A, Ratcliffe L, Nightingale A (2013) The carotid body as a therapeutic target for the treatment of sympathetically mediated diseases. Hypertension 61:5-13
101. Peers C (1990) Effect of lowered extracellular pH on Ca2(+)-dependent $\mathrm{K}+$ currents in type I cells from the neonatal rat carotid body. $\mathrm{J}$ Physiol 422:381-395

102. Peers C (1990) Hypoxic suppression of $K+$ currents in type I carotid body cells: selective effect on the $\mathrm{Ca} 2(+)$-activated $\mathrm{K}+$ current. Neurosci Lett 119:253-256

103. Peers C, Green FK (1991) Inhibition of $\mathrm{Ca}(2+)$-activated $\mathrm{K}+$ currents by intracellular acidosis in isolated type I cells of the neonatal rat carotid body. J Physiol 437:589-602

104. Peers C, O'Donnell J (1990) Potassium currents recorded in type I carotid body cells from the neonatal rat and their modulation by chemoexcitatory agents. Brain Res 522:259-266

105. Peng YJ, Nanduri J, Raghuraman G, Souvannakitti D, Gadalla MM, Kumar GK, Snyder SH, Prabhakar NR (2010) H2S mediates O2 sensing in the carotid body. Proc Natl Acad Sci U S A 107:10719 10724

106. Perez Garcia MT, Almaraz L, Gonzalez C (1991) Cyclic AMP modulates differentially the release of dopamine induced by hypoxia and other stimuli and increases dopamine synthesis in the rabbit carotid body. J Neurochem 57:1992-2000

107. Perez Garcia MT, Colinas O, Miguel Velado E, Moreno Dominguez A, Lopez Lopez JR (2004) Characterization of the Kv channels of mouse carotid body chemoreceptor cells and their role in oxygen sensing. J Physiol 557:457-471

108. Perez Garcia MT, Obeso A, Lopez Lopez JR, Herreros B, Gonzalez C (1992) Characterization of cultured chemoreceptor cells dissociated from adult rabbit carotid body. Am J Physiol 263:C1152C1159

109. Platero-Luengo A, Gonzalez-Granero S, Duran R, Diaz-Castro B, Piruat JI, Garcia-Verdugo JM, Pardal R, Lopez-Barneo J (2014) An $\mathrm{O} 2$-sensitive glomus cell-stem cell synapse induces carotid body growth in chronic hypoxia. Cell 156:291-303

110. Prabhakar NR (2012) Carbon monoxide (CO) and hydrogen sulfide $(\mathrm{H}(2) \mathrm{S})$ in hypoxic sensing by the carotid body. Respir Physiol Neurobiol 184:165-169

111. Prabhakar NR, Peng YJ, Jacono FJ, Kumar GK, Dick TE (2005) Cardiovascular alterations by chronic intermittent hypoxia: importance of carotid body chemoreflexes. Clin Exp Pharmacol Physiol $32: 447-449$

112. Rajan S, Wischmeyer E, Xin Liu G, Preisig Muller R, Daut J, Karschin A, Derst C (2000) TASK-3, a novel tandem pore domain acid-sensitive $\mathrm{K}+$ channel. An extracellular histiding as $\mathrm{pH}$ sensor. J Biol Chem 275:16650-16657

113. Rocher A, Geijo Barrientos E, Caceres AI, Rigual R, Gonzalez C, Almaraz L (2005) Role of voltage-dependent calcium channels in stimulus-secretion coupling in rabbit carotid body chemoreceptor cells. J Physiol 562:407-420

114. Rong W, Gourine AV, Cockayne DA, Xiang Z, Ford AP, Spyer KM, Burnstock G (2003) Pivotal role of nucleotide P2X2 receptor subunit of the ATP-gated ion channel mediating ventilatory responses to hypoxia. J Neurosci 23:11315-11321

115. Runold M, Cherniack NS, Prabhakar NR (1990) Effect of adenosine on isolated and superfused cat carotid body activity. Neurosci Lett 113:111-114

116. Schultz HD, Li YL (2007) Carotid body function in heart failure. Respir Physiol Neurobiol 157:171-185

117. Shen TCR, Hauss WH (1939) Influence of dinitrophenol, dinitroortocresol and paranitrophenol upon the carotid sinus chemoreceptors of the dog. Arch Int Pharmacodyn Ther 63:251-258

118. Sirois JE, Lynch C 3rd, Bayliss DA (2002) Convergent and reciprocal modulation of a leak $\mathrm{K}+$ current and $\mathrm{I}(\mathrm{h})$ by an inhalational anaesthetic and neurotransmitters in rat brainstem motoneurones. $\mathrm{J}$ Physiol 541:717-729

119. Slingo ME, Turner PJ, Christian HC, Buckler KJ (1985) Robbins PA (2014) The von Hippel-Lindau Chuvash mutation in mice 
causes carotid-body hyperplasia and enhanced ventilatory sensitivity to hypoxia. J Appl Physiol 116:885-892

120. Stea A, Nurse CA (1989) Chloride channels in cultured glomus cells of the rat carotid body. Am J Physiol 257:C174-C181

121. Stea A, Nurse CA (1991) Whole-cell and perforated-patch recordings from $\mathrm{O} 2$-sensitive rat carotid body cells grown in short- and long-term culture. Pflugers Arch 418:93-101

122. Sterni LM, Bamford OS, Tomares SM, Montrose MH, Carroll JL (1995) Developmental changes in intracellular Ca2+ response of carotid chemoreceptor cells to hypoxia. Am J Physiol 268:L801L808

123. Sylvester JT, Shimoda LA, Aaronson PI, Ward JP (2012) Hypoxic pulmonary vasoconstriction. Physiol Rev 92:367-520

124. Talley EM, Bayliss DA (2002) Modulation of TASK-1 (Kcnk3) and TASK-3 (Kcnk9) potassium channels: volatile anesthetics and neurotransmitters share a molecular site of action. J Biol Chem 277: 17733-17742

125. Talley EM, Lei Q, Sirois JE, Bayliss DA (2000) TASK-1, a twopore domain $\mathrm{K}+$ channel, is modulated by multiple neurotransmitters in motoneurons. Neuron 25:399-410

126. Tan ZY, Lu Y, Whiteis CA, Benson CJ, Chapleau MW, Abboud FM (2007) Acid-sensing ion channels contribute to transduction of extracellular acidosis in rat carotid body glomus cells. Circ Res 101: 1009-1019

127. Trapp S, Aller MI, Wisden W, Gourine AV (2008) A role for TASK1 (KCNK3) channels in the chemosensory control of breathing. J Neurosci 28:8844-8850

128. Trivedi B, Danforth WH (1966) Effect of $\mathrm{pH}$ on the kinetics of frog muscle phosphofructokinase. J Biol Chem 241:4110-4112

129. Turner PJ, Buckler KJ (2013) Oxygen and mitochondrial inhibitors modulate both monomeric and heteromeric TASK-1 and TASK-3 channels in mouse carotid body type-1 cells. J Physiol 591:59775998

130. Urena J, Lopez Lopez J, Gonzalez C, Lopez Barneo J (1989) Ionic currents in dispersed chemoreceptor cells of the mammalian carotid body. J Gen Physiol 93:979-999

131. Vandier C, Conway AF, Landauer RC, Kumar P (1999) Presynaptic action of adenosine on a 4-aminopyridine-sensitive current in the rat carotid body. J Physiol 515:419-429

132. Varas R, Wyatt CN, Buckler KJ (2007) Modulation of TASK-like background potassium channels in rat arterial chemoreceptor cells by intracellular ATP and other nucleotides. J Physiol 583:521-536

133. Veale EL, Buswell R, Clarke CE, Mathie A (2007) Identification of a region in the TASK 3 two pore domain potassium channel that is critical for its blockade by methanandamide. Br J Pharmacol 152: $778-786$
134. Ward DS, Karan SB, Pandit JJ (2011) Hypoxia: developments in basic science, physiology and clinical studies. Anaesthesia 66(Suppl 2):19-26

135. Weir EK, Lopez-Barneo J, Buckler KJ, Archer SL (2005) Acute oxygen-sensing mechanisms. N Engl J Med 353:2042-2055

136. Wilke BU, Lindner M, Greifenberg L, Albus A, Kronimus Y, Bunemann M, Leitner MG, Oliver D (2014) Diacylglycerol mediates regulation of TASK potassium channels by Gq-coupled receptors. Nat Commun 5:5540

137. Williams BA, Buckler KJ (2004) Biophysical properties and metabolic regulation of a TASK-like potassium channel in rat carotid body type 1 cells. Am J Physiol Lung Cell Mol Physiol 286: L221-L230

138. Wyatt CN, Buckler KJ (2003) The effect of methanandamide on isolated type I cells. Adv Exp Med Biol 536:123-127

139. Wyatt CN, Buckler KJ (2003) Effect of mitochondrial inhibitors on type I cells. Adv Exp Med Biol 536:55-58

140. Wyatt CN, Buckler KJ (2004) The effect of mitochondrial inhibitors on membrane currents in isolated neonatal rat carotid body type I cells. J Physiol 556:175-191

141. Wyatt CN, Mustard KJ, Pearson SA, Dallas ML, Atkinson L, Kumar P, Peers C, Hardie DG, Evans AM (2007) AMP-activated protein kinase mediates carotid body excitation by hypoxia. J Biol Chem 282:8092-8098

142. Xu F, Xu J, Tse FW, Tse A (2006) Adenosine stimulates depolarization and rise in cytoplasmic $[\mathrm{Ca} 2+]$ in type I cells of rat carotid bodies. Am J Physiol Cell Physiol 290:C1592C1598

143. Yamaguchi S, Lande B, Kitajima T, Hori Y, Shirahata M (2004) Patch clamp study of mouse glomus cells using a whole carotid body. Neurosci Lett 357:155-157

144. Zhang M, Buttigieg J, Nurse CA (2007) Neurotransmitter mechanisms mediating low-glucose signalling in cocultures and fresh tissue slices of rat carotid body. J Physiol 578:735-750

145. Zhang M, Fearon IM, Zhong H, Nurse CA (2003) Presynaptic modulation of rat arterial chemoreceptor function by 5-HT: role of $\mathrm{K}+$ channel inhibition via protein kinase C. J Physiol 551:825-842

146. Zhang M, Nurse CA (2000) Does endogenous 5-HT mediate spontaneous rhythmic activity in chemoreceptor clusters of rat carotid body? Brain Res 872:199-203

147. Zhang M, Nurse CA (2004) CO2/pH chemosensory signaling in cocultures of rat carotid body receptors and petrosal neurons: role of ATP and ACh. J Neurophysiol 92:3433-3445

148. Zhang M, Zhong H, Vollmer C, Nurse CA (2000) Co-release of ATP and ACh mediates hypoxic signalling at rat carotid body chemoreceptors. J Physiol 525(Pt 1):143-158 